Supporting Information for:

\title{
The Mechanism of Zeolite Hydrolysis under Basic Conditions
}

Mengting Jin ${ }^{\mathrm{a}}$, Mingxiu Liu ${ }^{\mathrm{a}}$, Petr Nachtigalla, Lukáš Grajciar ${ }^{\mathrm{a}}$, Christopher James Heard ${ }^{\text {a* }}$

a Department of Physical and Macromolecular Chemistry, Faculty of Science, Charles

University in Prague, 12843 Prague 2, Czech Republic

\section{*heardc@natur.cuni.cz}

\section{Sampling of AIMD trajectories}

a)

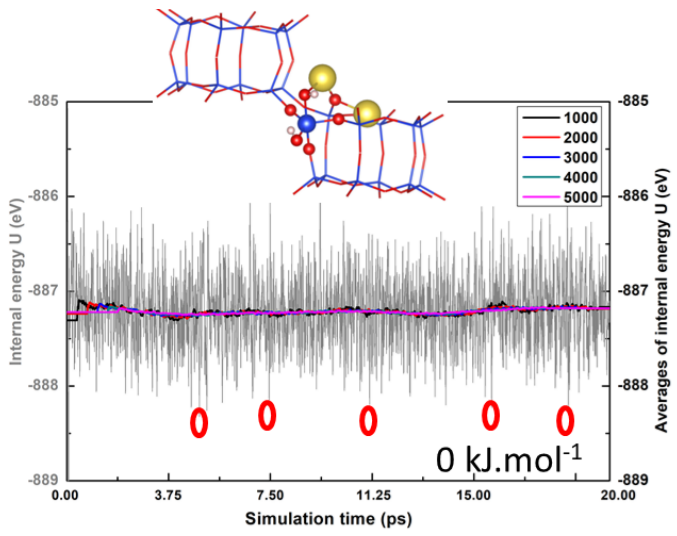

C)

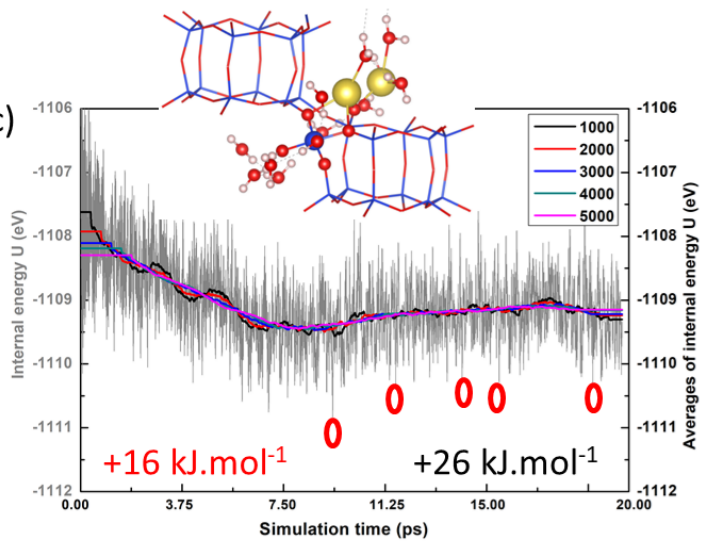

b)

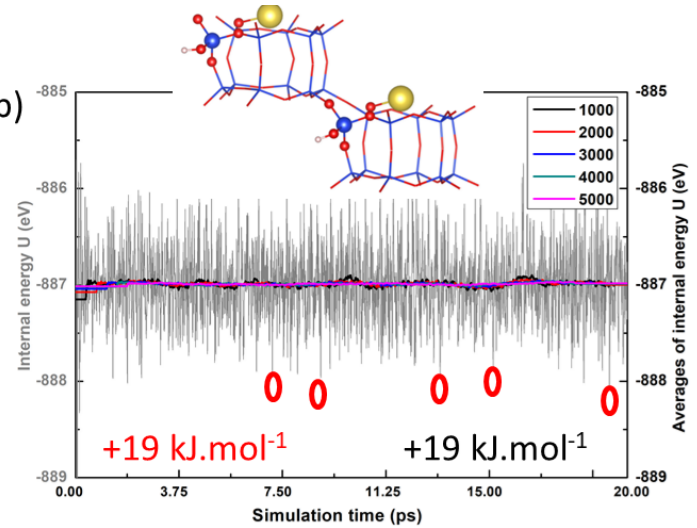

d)

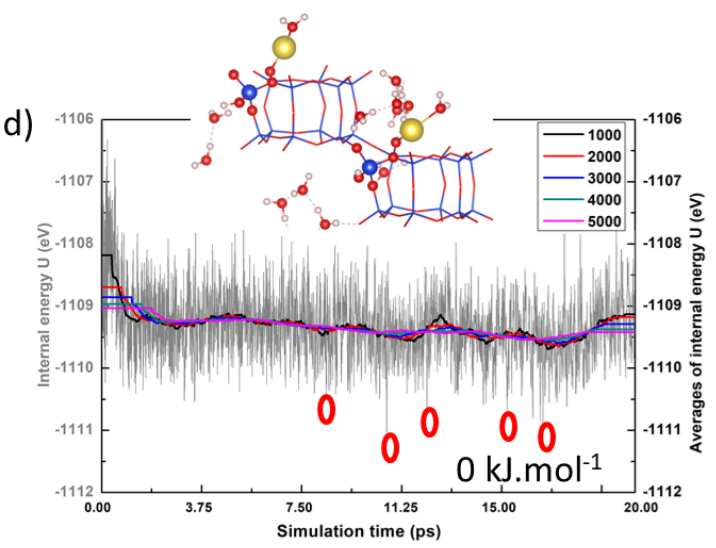

Figure S1: AIMD energy trajectories with relative running averages for selected $\mathrm{Q}^{3}$ configurations after the first step of the M2 mechanism under low $(a, b)$ and high $(c, d)$ water conditions. Energy averages from AIMD in black colour, minimum energy of representative local minima in red colour.

Running averaging was applied to obtain accurate averages for the internal energies of configurations along the AIMD trajectories in the same manner as in previous reports. ${ }^{1}$ The breath of the sampling bins was varied from 1000 to 5000 configurations per data point, and showed good convergence between running average traces for all simulations. This implies that the average internal energy is invariant to the bin width for these simulations. Reported average internal energies are given by the final value of the running average, which ensures that no spurious contributions are collected from un-equilibrated configurations at the start of 
the simulation. Electronic energies were determined via local geometry optimization of several configurations (highlighted by red ovals) after the equilibration phase (relative electronic energies are highlighted in black colour). This allows for direct comparison with energetics from static calculations elsewhere in the work. Relatively small deviations were observed in the energies between the two methods, as shown by comparison of red (static) and black (AIMD average) values.

\section{Entropic Considerations}

The activation energies for a forward step presented herein are electronic energies, based on $d E=E(T S)-E(I S)$. This is an approximation to the free energy of activation $d G=d H-$ $T d S$, in which the enthalpy change between initial and transition states is approximated by the electronic energy change, and the entropic contribution is neglected. Entropic corrections can be made, according to $d S=S(T S)-S(I S)$, where $\mathrm{S}$ is extracted from the frequencies of the vibrational modes calculated from diagonalization of the harmonic Hessian matrix. ${ }^{2}$ For steps in various mechanisms, we have calculated this approximate entropic contribution, and find the effect is small at $300 \mathrm{~K}$, generally modifying dG by less than $10 \%$. Hence, we neglect the contributions, and thereby avoid the additional approximations that such corrections impose. ${ }^{3,4}$ Below are recalculated example steps according to the minimal water $\mathrm{M} 1, \mathrm{M} 2$ and $\mathrm{M} 3 \mathrm{Q}^{3} \rightarrow \mathrm{Q}^{2}$ mechanisms, with the vibrational entropy correction included.

\section{Transition state imaginary frequencies}

M1:

Q4-Q3:

O1-TS1 $\mathrm{f} / \mathrm{i}=254.204288 \mathrm{~cm}^{-1}$
O1-TS2 $\mathrm{f} / \mathrm{i}=63.407797 \mathrm{~cm}^{-1}$

Q3-Q2:

O3-TS $\mathrm{f} / \mathrm{i}=579.954497 \mathrm{~cm}^{-1}$

Q2-Q1:

O2-TS $\mathrm{f} / \mathrm{i}=\quad 305.842276 \mathrm{~cm}^{-1}$

Q1-Q0:

O4-TS $\mathrm{f} / \mathrm{i}=251.494251 \mathrm{~cm}^{-1}$

M2:

Q4-Q3:

O1-TS $\mathrm{f} / \mathrm{i}=58.816223 \mathrm{~cm}-1$

Q3-Q2:

O3-TS $\mathrm{f} / \mathrm{i}=62.857556 \mathrm{~cm}-1$ 
Q2-Q1:

O2-TS $\mathrm{f} / \mathrm{i}=66.757865 \mathrm{~cm}-1$

Q1-Q0:

O4-TS $\mathrm{f} / \mathrm{i}=61.578864 \mathrm{~cm}-1$

\section{M3-1H2O:}

Q3-Q2:

TS1-reg $\mathrm{f} / \mathrm{i}=78.784637 \mathrm{~cm}-1$

TS2-mig $\mathrm{f} / \mathrm{i}=23.557170 \mathrm{~cm}-1$

TS3-sci $\mathrm{f} / \mathrm{i}=56.948832 \mathrm{~cm}-1$

Q2-Q1:

TS1-reg $\mathrm{f} / \mathrm{i}=364.777763 \mathrm{~cm}-1$

TS2-sci $\mathrm{f} / \mathrm{i}=30.558640 \mathrm{~cm}-1$

Q1-Q0:

TS1-reg $\mathrm{f} / \mathrm{i}=347.292490 \mathrm{~cm}-1$

TS2-sci $\mathrm{f} / \mathrm{i}=52.405721 \mathrm{~cm}-1$

M3-2H2O:

Q3-Q2:

TS1-mig $\mathrm{f} / \mathrm{i}=18.610365 \mathrm{~cm}-1$

TS2-reg $\quad \mathrm{f} / \mathrm{i}=289.028868 \mathrm{~cm}-1$

TS3-sci $\mathrm{f} / \mathrm{i}=44.005090 \mathrm{~cm}-1$

Q2-Q1:

TS1-mig $\mathrm{f} / \mathrm{i}=31.660151 \mathrm{~cm}-1$

TS2-reg $\mathrm{f} / \mathrm{i}=75.043336 \mathrm{~cm}-1$

TS3-sci $\mathrm{f} / \mathrm{i}=42.097981 \mathrm{~cm}-1$

Q1-Q0:

TS1-mig $\mathrm{f} / \mathrm{i}=27.769323 \mathrm{~cm}-1$

TS2-reg $\mathrm{f} / \mathrm{i}=223.509449 \mathrm{~cm}-1$

TS3-sci $\quad \mathrm{f} / \mathrm{i}=33.270908 \mathrm{~cm}-1$ 

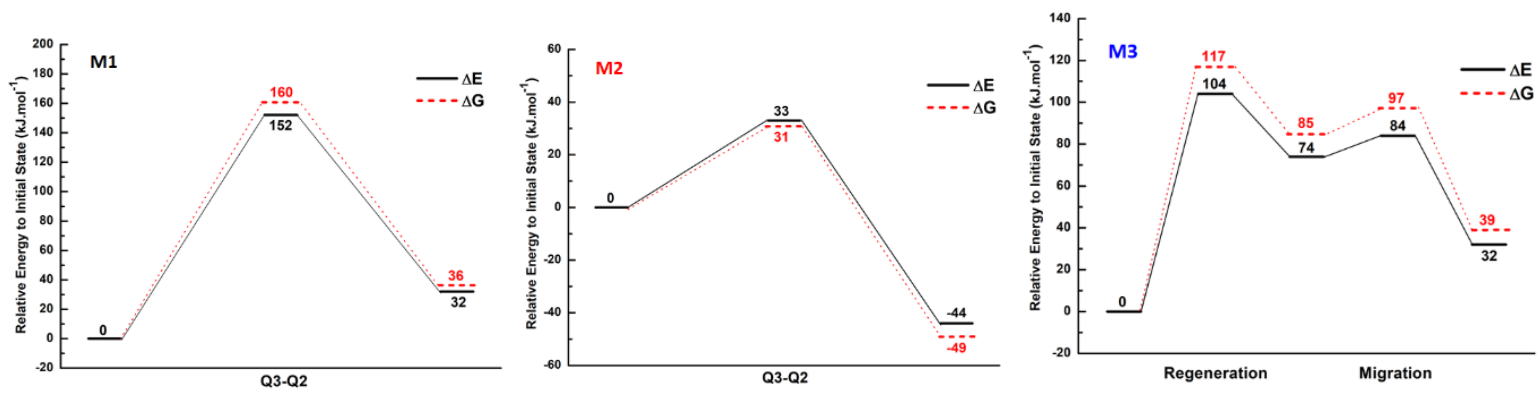

Figure S2: Comparison of $\mathrm{dE}$ and $\mathrm{dG}$ for selected mechanisms.

\section{Liquid Water AIMD reference}

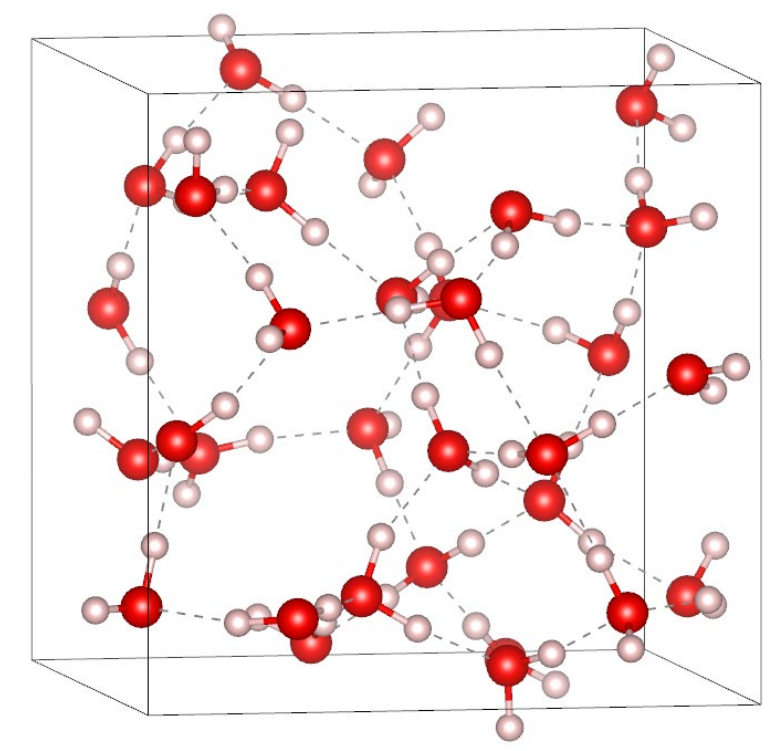

Figure S3: Structure of liquid water used as the reference for water incorporation into the zeolite framework. Per-water total energy $\left(\mathrm{E}_{\mathrm{H} 2 \mathrm{O}(\mathrm{l})}\right.$ in the main text, equation 4$)$ is determined by local geometry optimization of a converged liquid state that was generated via a 20 ps AIMD simulation of a cubic box (a,b,c=9.861 $\AA$ ), containing 31 water molecules. Per-water stabilisation of water molecules in liquid is calculated to be 65.7 $\mathrm{kJ} . \mathrm{mol}^{-1}$ with respect to a single water molecule in vacuo. 


\section{M1 full desilication mechanism}
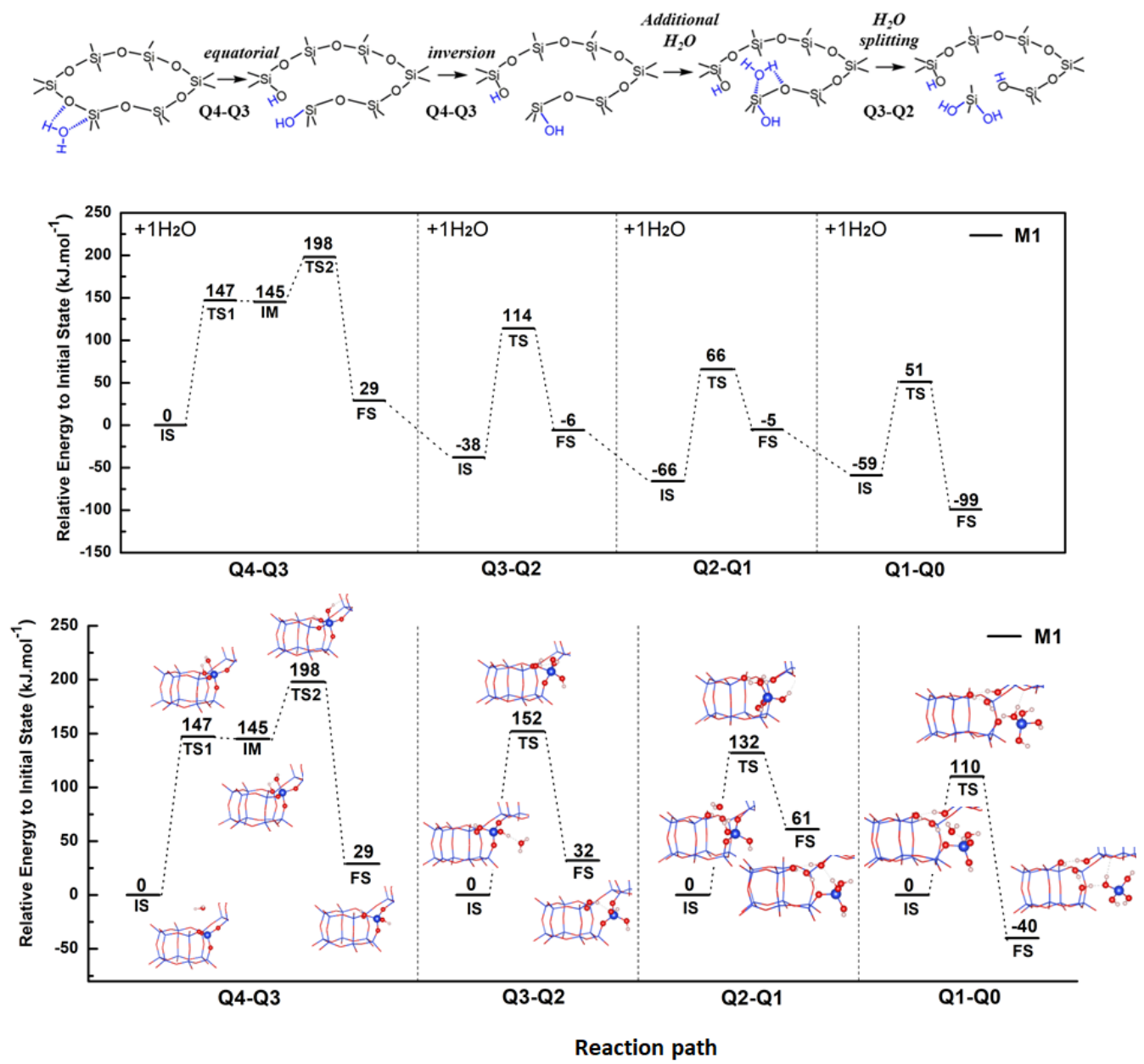

Figure S4: Full desilication pathway along the M1 mechanism under minimal water conditions. Top) Schematic of $\mathrm{Q}^{4} \rightarrow \mathrm{Q}^{3} \rightarrow \mathrm{Q}^{2}$ pathway. (Subsequent steps follow the same pathway as the $\mathrm{Q}^{3} \rightarrow \mathrm{Q}^{2}$ step). Middle) The full, connected reaction pathway from $\mathrm{Q}^{4} \rightarrow \mathrm{Q}^{0}$ with isolated water molecules as the reference for each step.

Below) The individual reaction steps with the initial states of individual steps as references. The intrinsic barriers decrease along the pathway, owing to the increased flexibility of the defect site and ease of access for reacting water.

\section{Silanol nest structures}

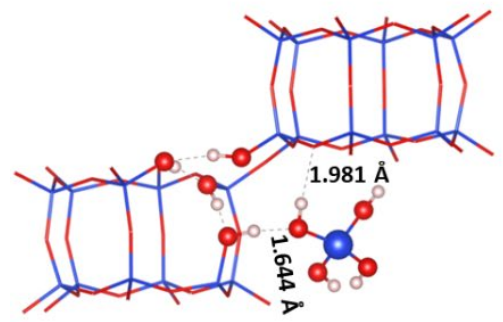

a)

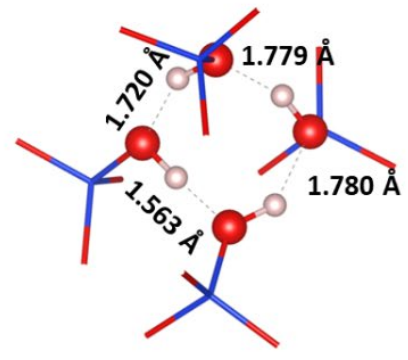

b)

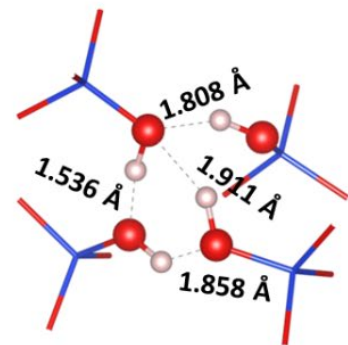

c) 
Figure S5: Structures of the silanol nests formed by the M1 mechanism. a) The product of hydrolysis, with silicic acid bound to the defect site, b) The optimal empty silanol nest, with an uninterrupted hydrogen bond network, c) Suboptimal silanol nest structure with a 3-membered hydrogen bond ring $(+21 \mathrm{~kJ} / \mathrm{mol})$.

\section{Further steps along the M2 mechanism}
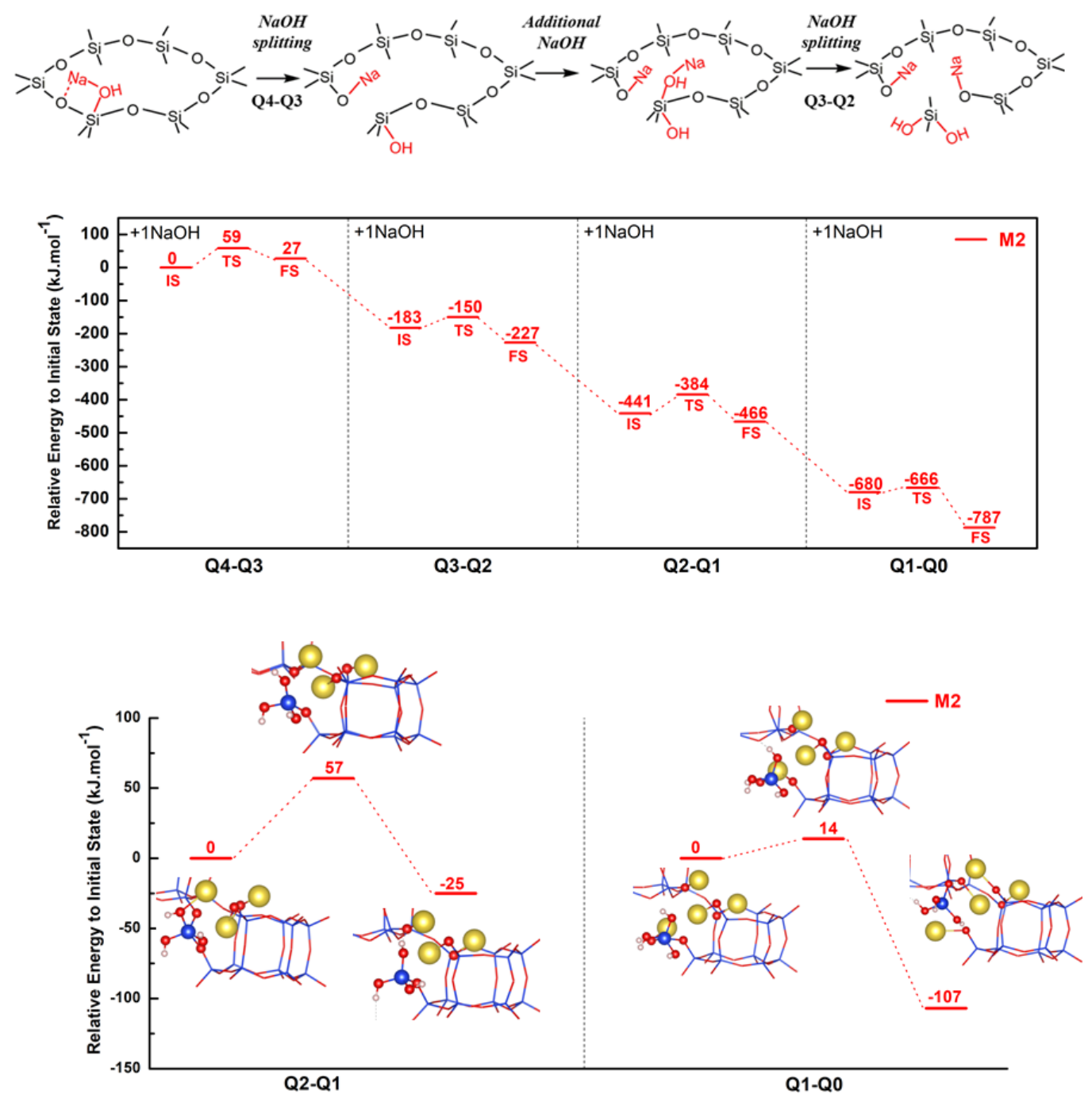

Figure S6: Full desilication pathway along the M2 mechanism under minimal water conditions. Top)

Schematic of $\mathrm{Q}^{4} \rightarrow \mathrm{Q}^{3} \rightarrow \mathrm{Q}^{2}$ pathway. (Subsequent steps follow the same pathway as the $\mathrm{Q}^{3} \rightarrow \mathrm{Q}^{2}$ step). Middle) The full, connected reaction pathway from $\mathrm{Q}^{4} \rightarrow \mathrm{Q}^{0}$ with isolated $\mathrm{NaOH}$ molecules as the reference for each step.

Below) The individual reaction steps with the initial states of individual steps as references.

\section{Substitution between silanol and sodium silanolate nests}

The substitution energy for replacement of silanol groups with sodium silanolate groups was calculated via the following equation:

$\mathrm{E}_{\text {sub }}=\mathbf{E}\left(\mathrm{Si}(\mathrm{OH})_{4-\mathrm{n}}(\mathrm{ONa})_{\mathrm{n}}\right)+\mathrm{n} \mathbf{E}\left(\mathrm{H}_{2} \mathrm{O}\right)-\mathbf{E}\left(\mathrm{Si}(\mathrm{OH})_{4}\right)-\mathrm{n} \mathbf{E}(\mathrm{NaOH})$ 
Where $\mathrm{E}_{\mathrm{Si}(\mathrm{OH}) 4-\mathrm{n}(\mathrm{ONa}) \mathrm{n}}$ is the total energy for the substituted silanol/silanolate nest, in which $\mathrm{n}$ $\mathrm{OH}$ groups have been replaced with $\mathrm{ONa}$ groups. $\mathrm{E}_{\mathrm{Si}(\mathrm{OH}) 4}$ is the total energy for the most stable configuration with a pure silanol nest. $\mathrm{E}_{\mathrm{H} 2 \mathrm{O}}$ is the energy difference between $\mathrm{H}_{2} \mathrm{O}$ adsorbed in to a silanol nest and the empty silanol nest, and $\mathrm{E}_{\mathrm{NaOH}}$ is the energy difference between non-dissociated $\mathrm{NaOH}$ adsorbed at a silanol nest, and the empty silanol nest. By defining the references in this way, we consider the realistic situation of water and $\mathrm{NaOH}$ occupying binding sites in a reservoir of unconnected silanol nests, rather than as single molecules in the gas phase.
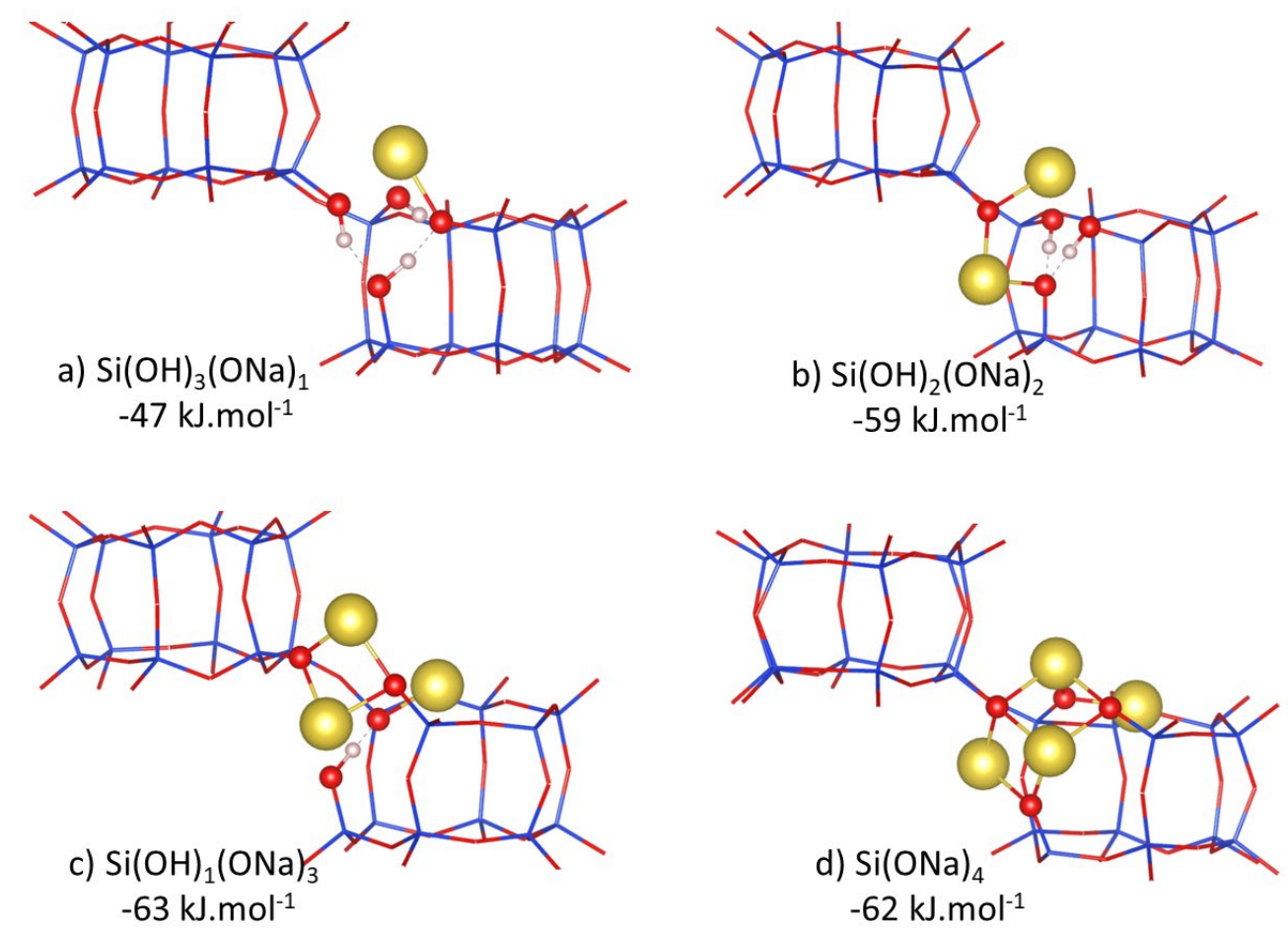

Figure S7: Structures and substitution energies $\left(\mathrm{E}_{\mathrm{sub}}\right)$ for the silanol/silanolate nest defect after full desilication with $0-4 \mathrm{Na}$ atoms.

\section{Alternative "Na-spectator" mechanism}




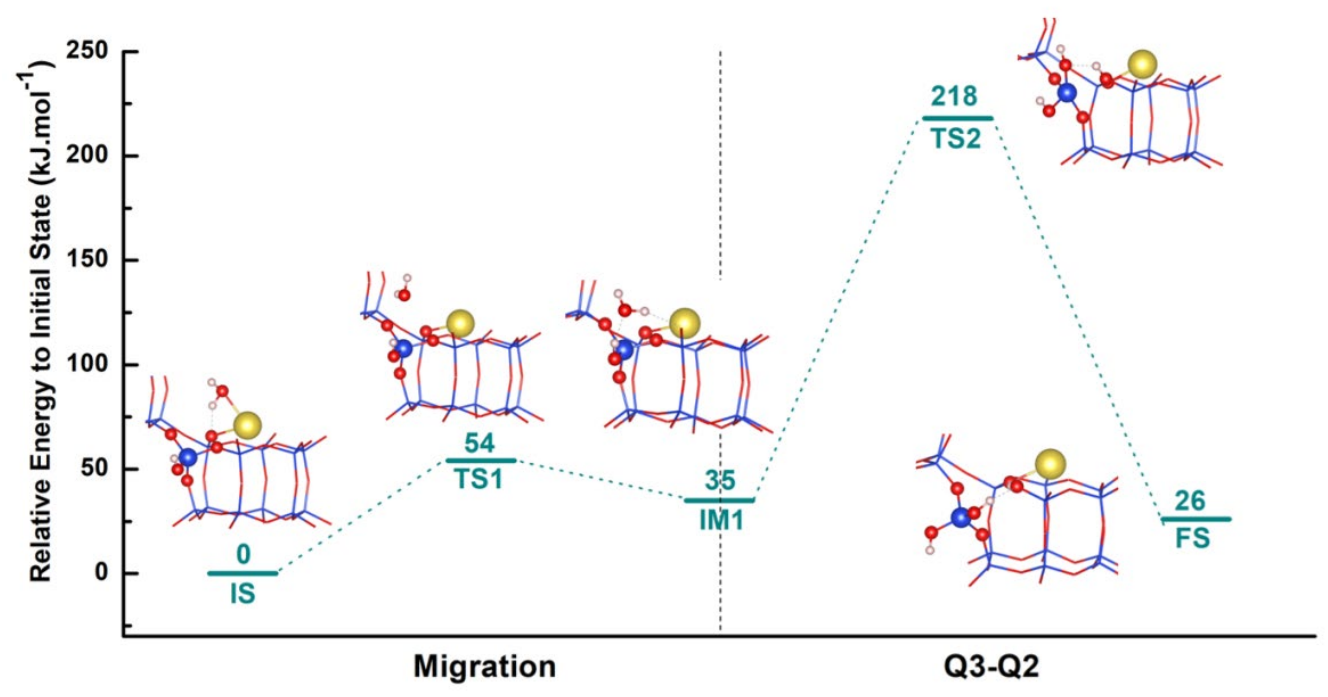

Figure S8: Structures and energies of stationary points along the alternative "Na-spectator" mechanism from

$$
\mathrm{Q}^{3} \rightarrow \mathrm{Q}^{2}
$$

\section{Analysis of Na-CHA interactions}

In the defective framework that results from the initial $\mathrm{Na}-\mathrm{OH}$ driven hydrolysis step, two $\mathrm{Q}^{3}$ silicon defects are created. The positively charged defect is terminated by an $\mathrm{OH}$ group and the negatively charged silanolate is terminated by a sodium cation. Analysis of the environment around the defects shows that the interaction between $\mathrm{Na}^{+}$and the oxygen atom of the framework $\mathrm{Q}^{3}$ silanolate $\left(\mathrm{O}_{\mathrm{f}}\right)$ is stable, even in the presence of water molecules. The $\mathrm{Na}-\mathrm{O}_{\mathrm{f}}$ distance oscillates around an average value of $2.335 \AA$, without dissociation and solvation over the course of the simulation. Trajectories of the Na cation are shown in figure $\mathrm{S}$, highlighting the small degree of $\mathrm{Na}^{+}$mobility, which is centred on the centre of the broken 6-ring face of the CHA double 6-ring. 
a)

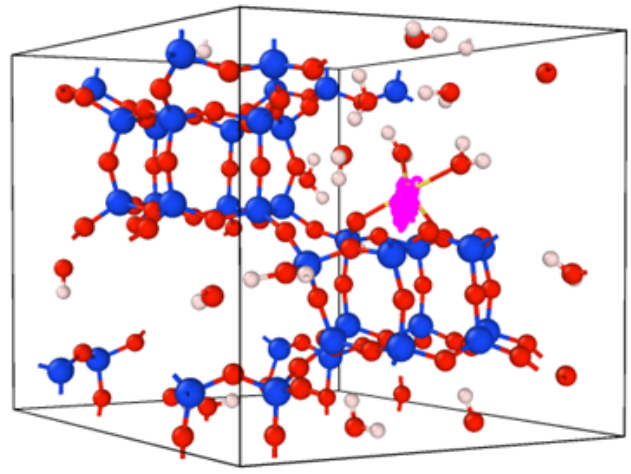

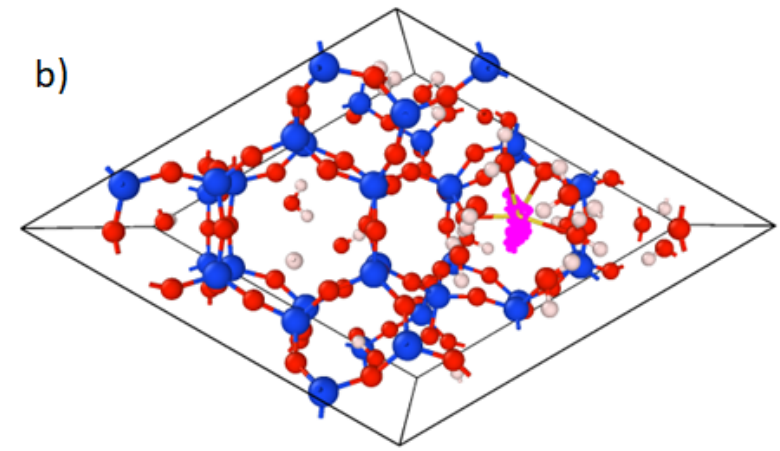

c)

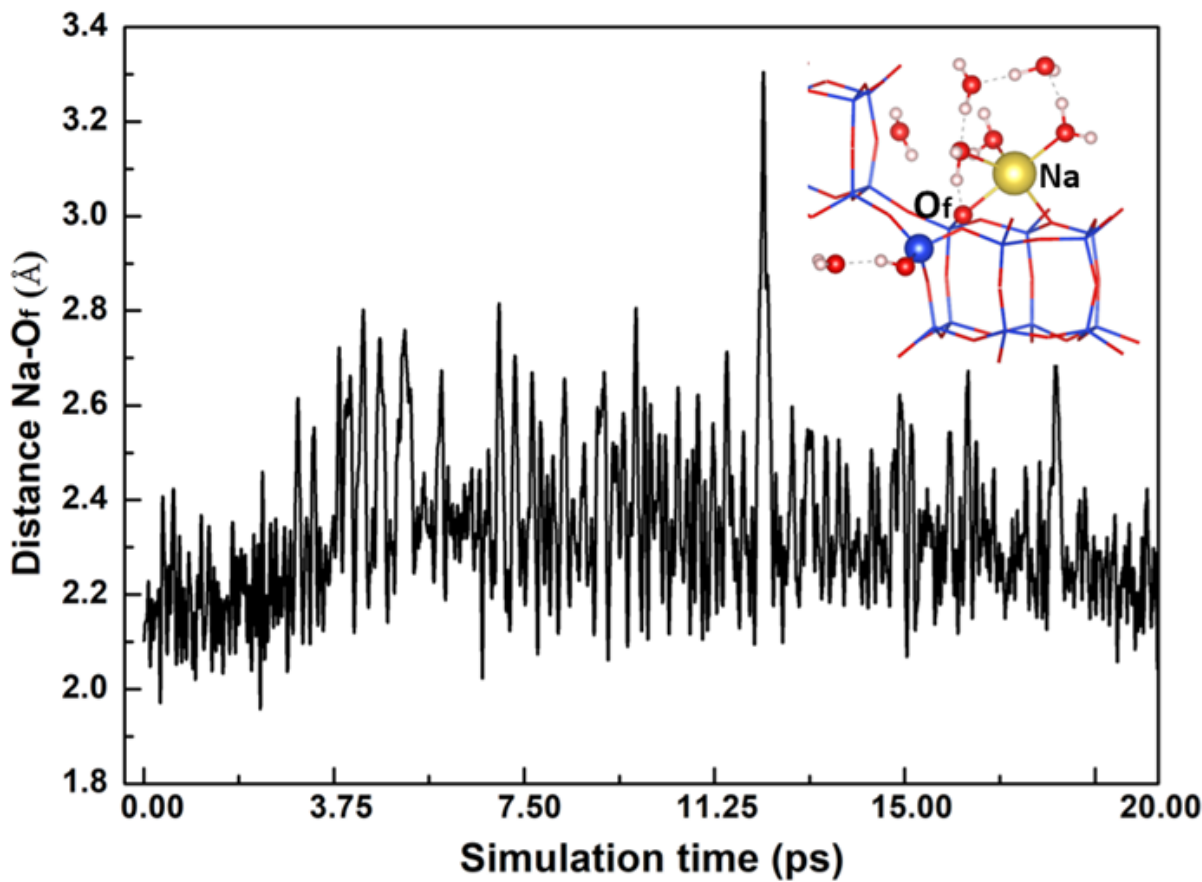

Figure S9: Mobility of the $\mathrm{Na}^{+}$ion in the $\mathrm{Q}^{3}$ product state under full solvation conditions, from 20 ps AIMD simulation at $300 \mathrm{~K}$. a) Side view of the CHA unti cell, with the total trajectory of the Na ion highlighted in pink colour. b) View projected down the axis normal to the CHA double 6-ring, with the total trajectory of the Na ion highlighted in pink colour. c) Distance trace for the $\mathrm{Na}-\mathrm{O}_{\mathrm{f}}$ bond over the course of the simulation.

\section{Analysis of $\mathrm{Na}-\mathrm{H}_{2} \mathrm{O}$ interactions}

Water molecules are observed to organise around the $\mathrm{Na}^{+}$cation to form distinct solvation shells which are stable over the timescale of the AIMD simulation. The configuration which is maintained throughout the simulation is one in which $\mathrm{Na}^{+}$forms two bonds to framework oxygen atoms, and approximately three bonds to water oxygen atoms (figure S10d). One framework oxygen is the silanolate oxygen formed by the preceding siloxane scission step. The other is a saturated framework oxygen in the 6-ring. The identify of this oxygen atom changes throughout the simulation, as the $\mathrm{Na}^{+}$moves slightly around the centre of the broken 6-ring. Because the timescale of water exchange for the water molecules closest to $\mathrm{Na}^{+}$is longer than the simulation timescale, the identities of the three water molecules that are strongly bound to $\mathrm{Na}^{+}$do not change over the simulation and we can therefore label them $\mathrm{W} 1$, W2 and W3 (figure S10) and use them to identify the first coordination shell of $\mathrm{Na}^{+}$. The 
bond lengths between these water molecules and $\mathrm{Na}^{+}$remain short throughout the simulation (figure S10b) and have average bond lengths of $2.577 \AA, 2.462 \AA$, and $2.416 \AA$, respectively. The trajectories of $\mathrm{W} 1, \mathrm{~W} 2$ and $\mathrm{W} 3$ are shown in figure S10c.

a)

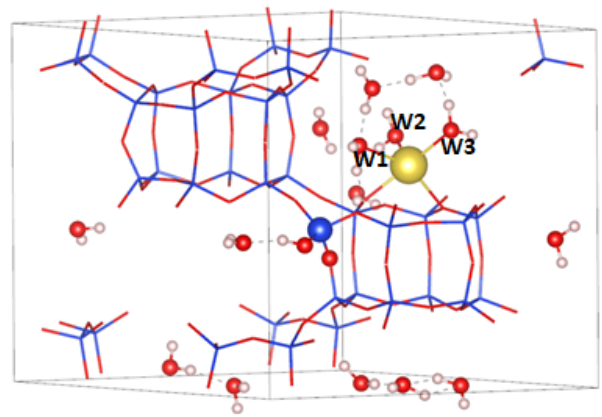

c)

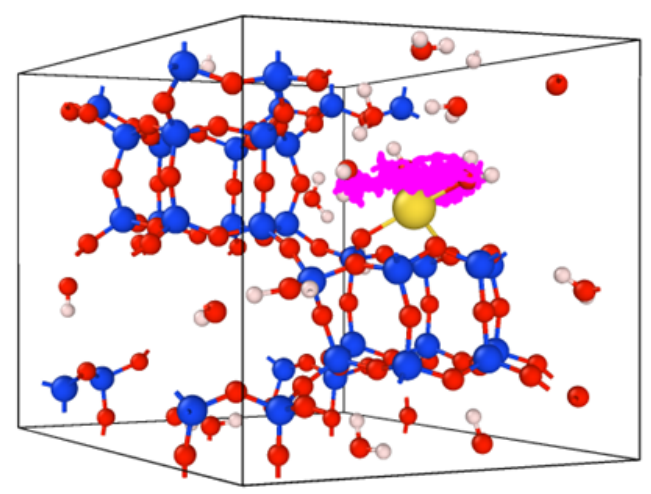

b)

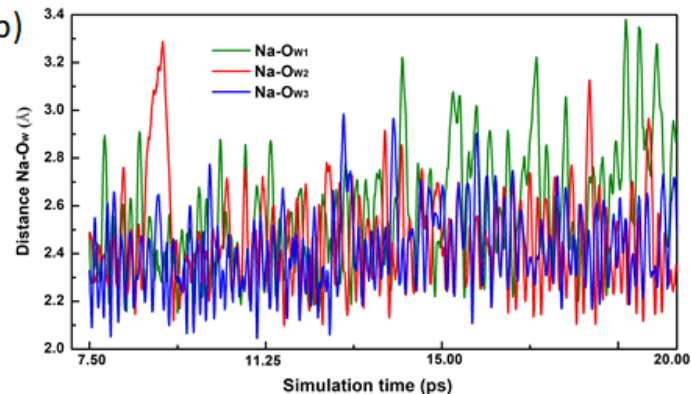

d)

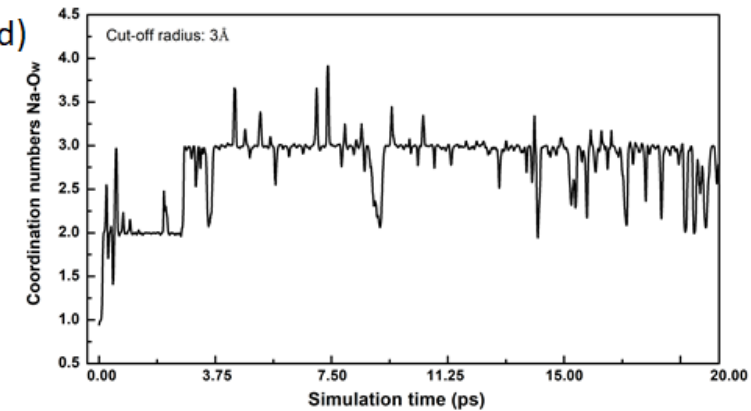

Figure S10: Snapshot at $t=7.5 \mathrm{ps}$ of the Q3 product state under full solvation conditions, taken from a $20 \mathrm{ps}$ AIMD simulation at $300 \mathrm{~K}, \mathrm{~b}$ ) Trace of the bond lengths between $\mathrm{Na}+$ and the three closest water molecules, $\mathrm{W} 1, \mathrm{~W} 2$ and $\mathrm{W} 3$ along the AIMD simulation, c)Trajectory of the Na+ ion during the AIMD simulation shown in pink colour, d) The coordination number between $\mathrm{Na}+$ and water oxygen atoms during the simulation, employing a cut-off distance of $3.0 \AA$ for Na-Ow bonding.

Calculation of the root mean squared deviations of the $\mathrm{Na}-\mathrm{O}_{\mathrm{w}}$ distances for all fifteen water molecules inside the zeolite pore further highlights that there is a clear distinction between first shell water molecules and others. W1, W2 and W3 (highlighted in bold in the Table) have low average deviations, due to the tight binding to the sodium cation. W8 (highlighted in italics in the Table) also has a notably low deviation. This is due to the low mobility induced by the strong hydrogen bond between W8 and the silanol group on the second $\mathrm{Q}^{3}$ silicon. It is also notable that the distribution of water is heterogenous, with several shells of water molecules interacting directly and indirectly with the sodium ion, but only one molecule directly attached to the silanol group. This supports the findings in figure 4 and Table 1 from static calculations of the preferred water locations. 


\begin{tabular}{|c|c|}
\hline Bond Label & RMSD (Å) \\
\hline $\mathrm{Na}-\mathrm{O}_{\mathrm{w}} 1$ & 0.258 \\
\hline $\mathrm{Na}-\mathrm{O}_{\mathrm{w}} 2$ & 0.207 \\
\hline $\mathrm{Na}-\mathrm{O}_{\mathrm{w}} 3$ & 0.186 \\
\hline $\mathrm{Na}-\mathrm{O}_{\mathrm{w}} 4$ & 0.816 \\
\hline $\mathrm{Na}-\mathrm{O}_{\mathrm{w}} 5$ & 0.416 \\
\hline $\mathrm{Na}-\mathrm{O}_{w} 6$ & 0.601 \\
\hline $\mathrm{Na}-\mathrm{O}_{\mathrm{w}} 7$ & 1.026 \\
\hline $\mathrm{Na}-\mathrm{O}_{w} 8$ & 0.421 \\
\hline $\mathrm{Na}-\mathrm{O}_{\mathrm{w}} 9$ & 1.072 \\
\hline $\mathrm{Na}-\mathrm{O}_{\mathrm{w}} 10$ & 0.913 \\
\hline $\mathrm{Na}-\mathrm{O}_{w} 11$ & 0.474 \\
\hline $\mathrm{Na}-\mathrm{O}_{\mathrm{w}} 12$ & 0.591 \\
\hline $\mathrm{Na}-\mathrm{O}_{\mathrm{w}} 13$ & 1.585 \\
\hline $\mathrm{Na}-\mathrm{O}_{w} 14$ & 0.815 \\
\hline $\mathrm{Na}-\mathrm{O}_{w} 15$ & 0.585 \\
\hline
\end{tabular}

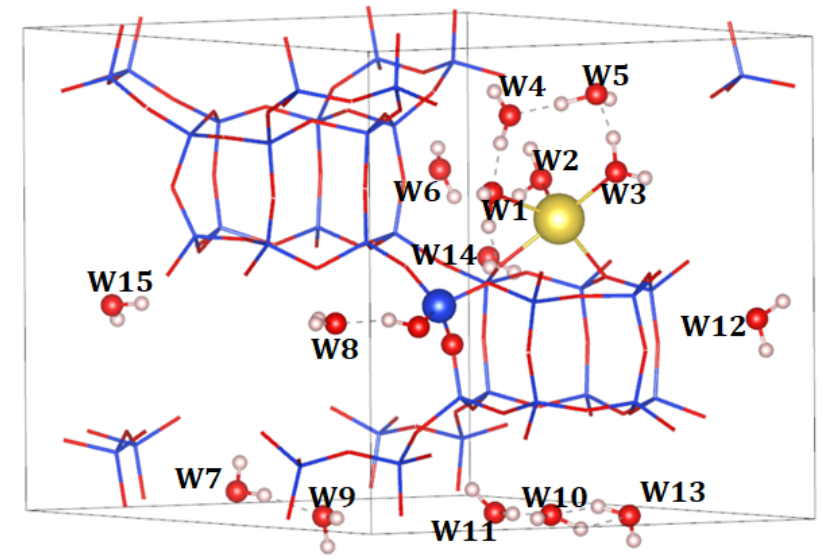

Figure S11: The RMSD of the distance between water oxygen atoms and the sodium cation calculated between $\mathrm{t}=7.5 \mathrm{ps}$ and $\mathrm{t}=20 \mathrm{ps}$. The three water molecules in the first coordination shell are highlighted in bold, and the water bound to the silanol group is highlighted in italics.

\section{Clustering of sodium in the M2 mechanism}

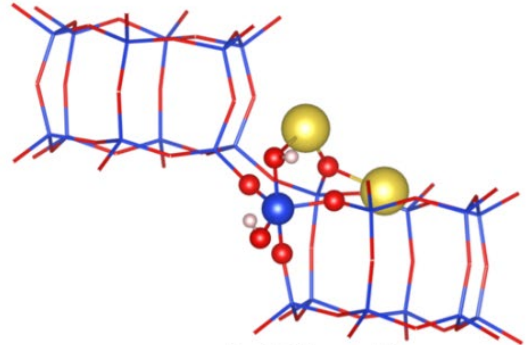

a) $0 \mathrm{~kJ} \cdot \mathrm{mol}^{-1}$

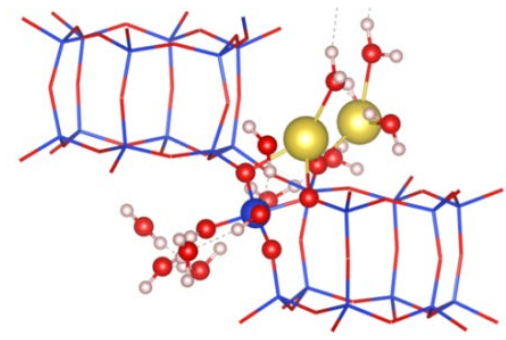

c) $+16 \mathrm{~kJ} \cdot \mathrm{mol}^{-1}$

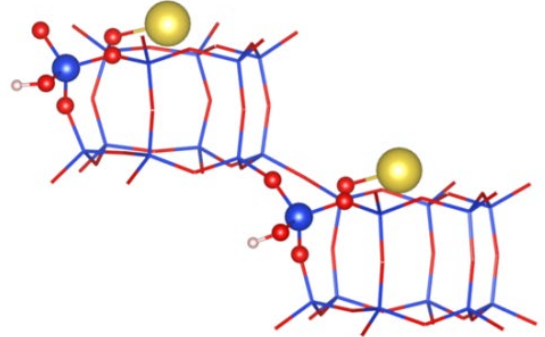

b) $+19 \mathrm{~kJ} \cdot \mathrm{mol}^{-1}$

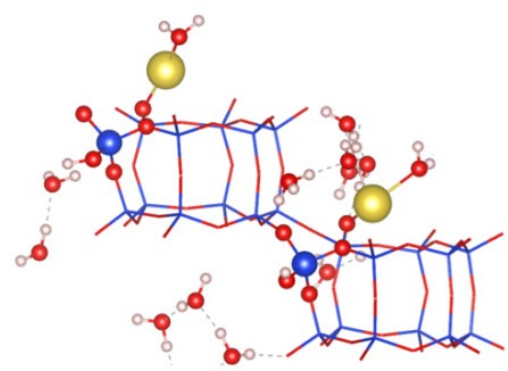

d) $0 \mathrm{~kJ} \cdot \mathrm{mol}^{-1}$

Figure S12: Structures of the $\mathrm{Q}^{3} \mathrm{Si}$ defect(s) after the first M2 step in excess $\mathrm{NaOH}$. a) Clustered configuration under anhydrous conditions, b) Non-clustered configuration under anhydrous conditions, in which the second $\mathrm{NaOH}$ molecule forms a second $\mathrm{Q}^{3}$ defect, c) Clustered configuration under fully hydrated conditions, d) Nonclustered configuration under fully hydrated conditions. 


\section{Further steps along the M3 mechanism}
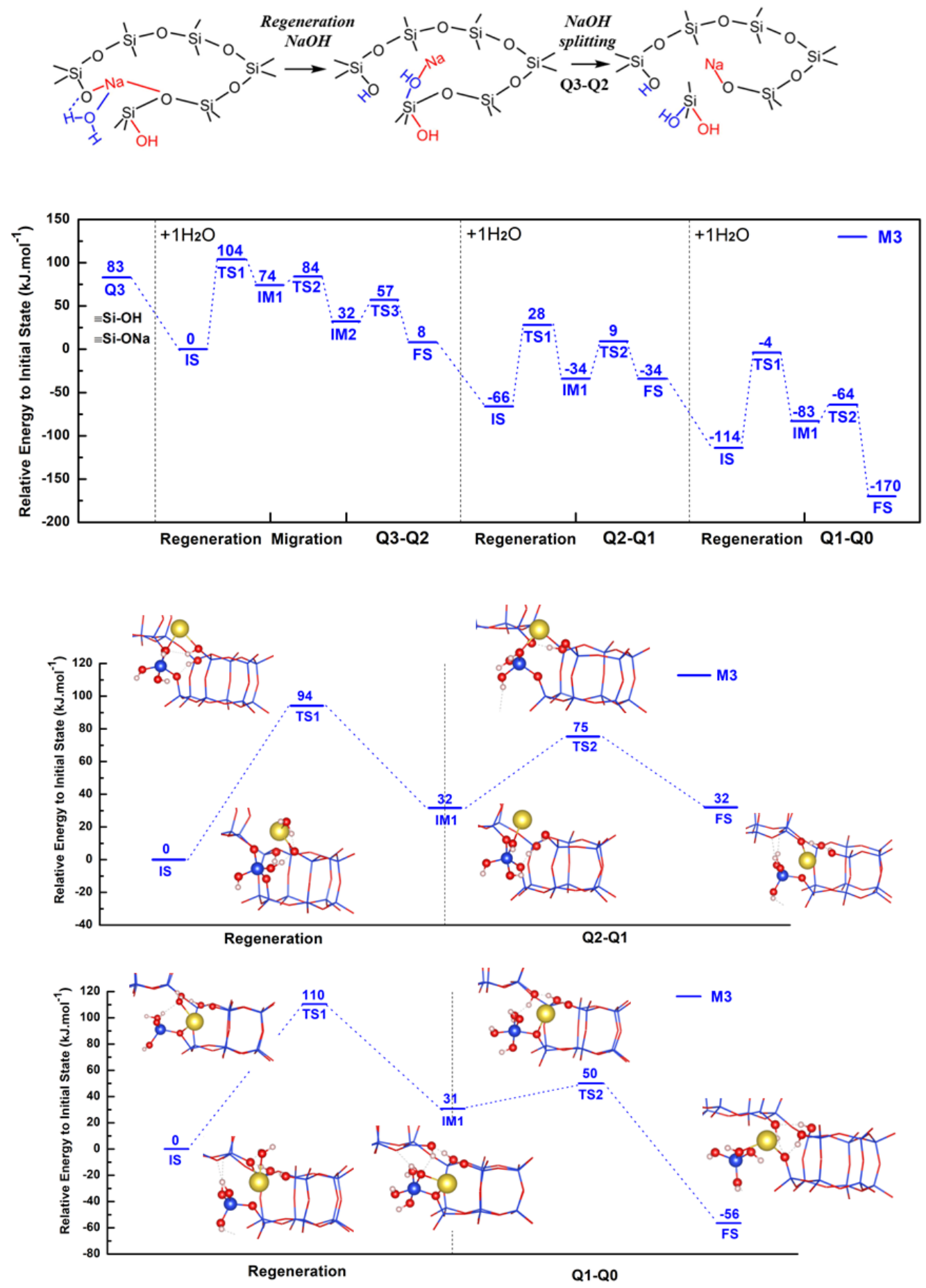

Figure S13: Full desilication pathway along the $\mathrm{M} 3$ mechanism under minimal water conditions. Top) Schematic of $\mathrm{Q}^{3} \rightarrow \mathrm{Q}^{2}$ pathway. Middle) The full, connected reaction pathway from $\mathrm{Q}^{3} \rightarrow \mathrm{Q}^{0}$. Below) The individual reaction steps with the initial states of individual steps as references.

\section{Alternative M3 mechanism}




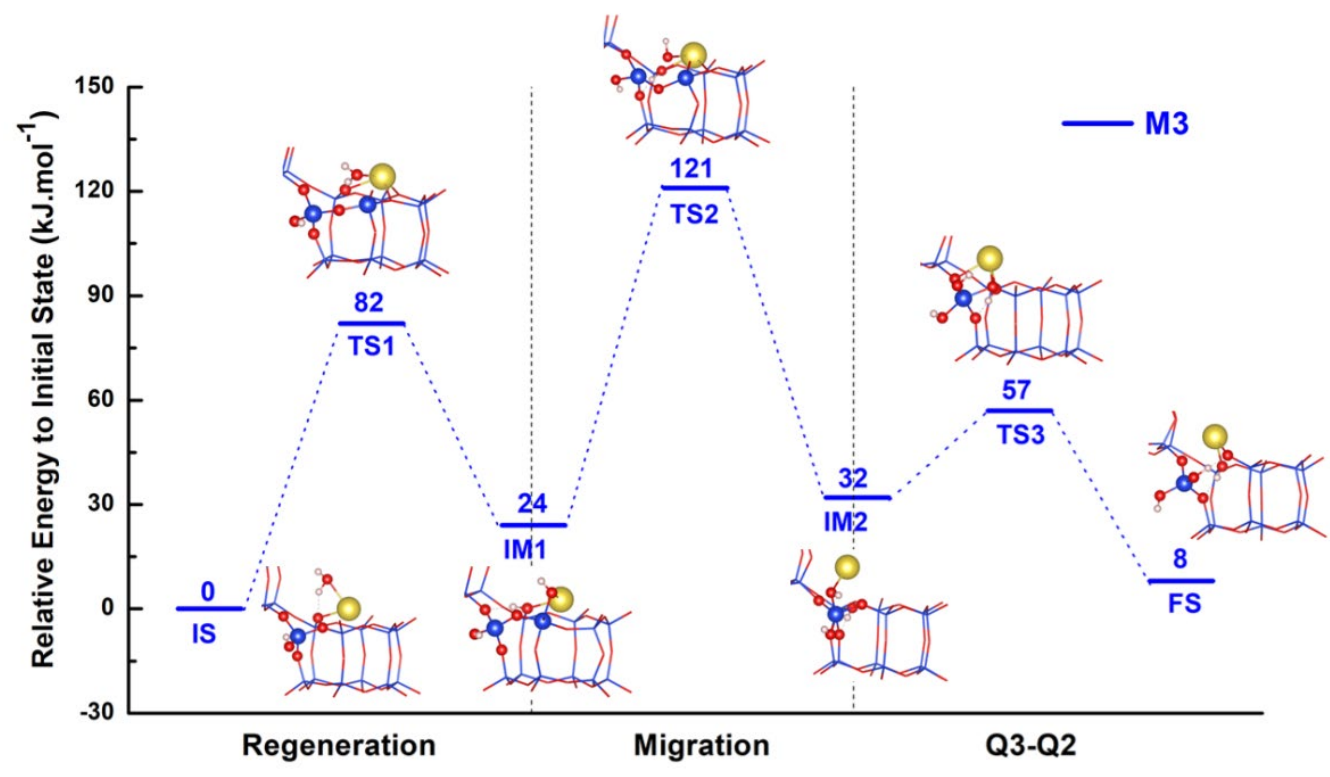

Figure S14: Structures and energetics of the alternative low water M3 mechanism. In this alternative, $\mathrm{NaOH}$ is regenerated at a pristine $\mathrm{Q}^{4} \mathrm{Si}$ site, rather than directly at the $\mathrm{Q}^{3} \mathrm{Si}$ defect site. It then undergoes a migration step to reach the $\mathrm{Q}^{3}$ defect. This pathway has an effective barrier of $121 \mathrm{~kJ} / \mathrm{mol}$, and is therefore uncompetitive.

\section{M3 mechanism under microsolvation}
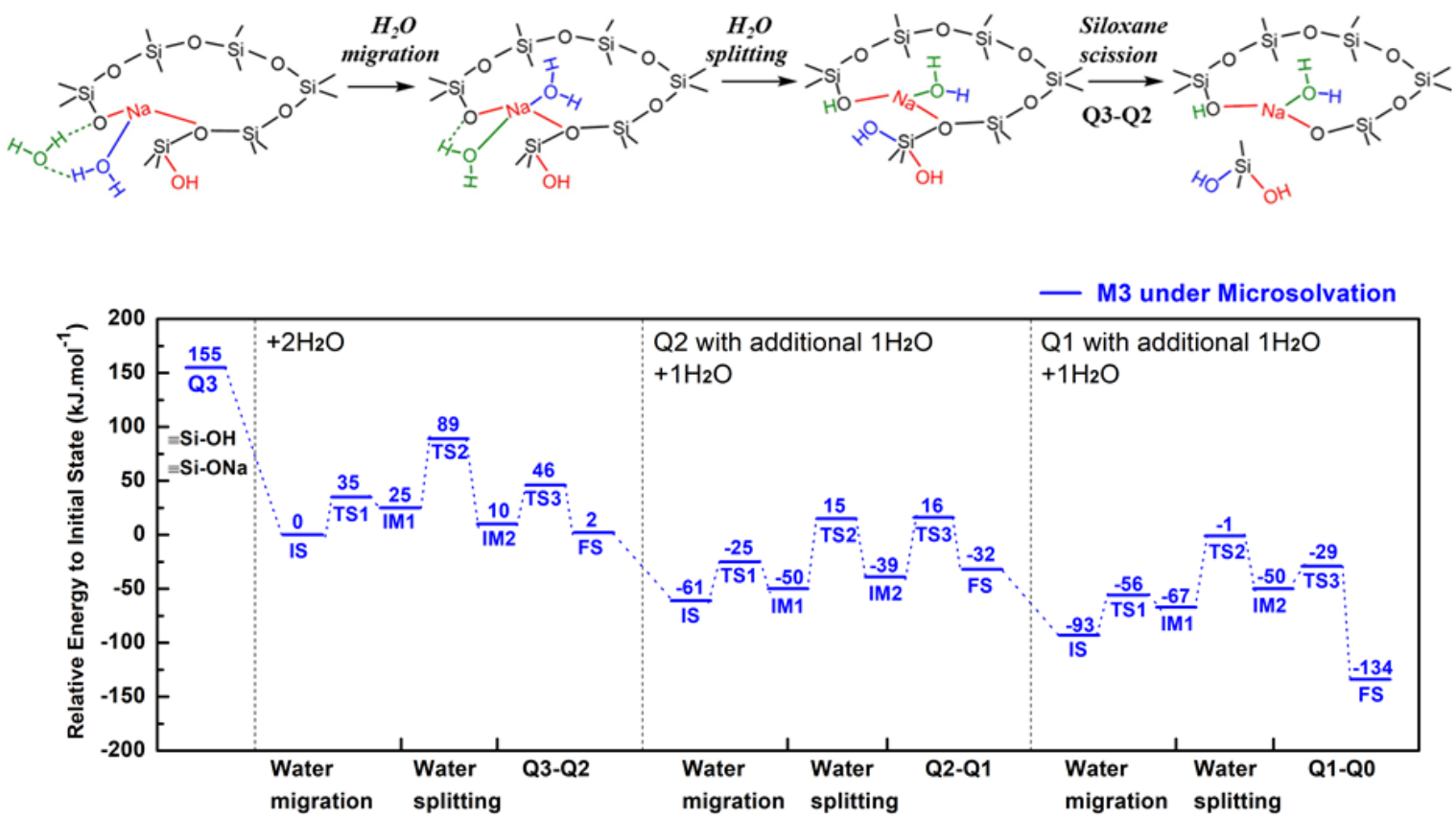


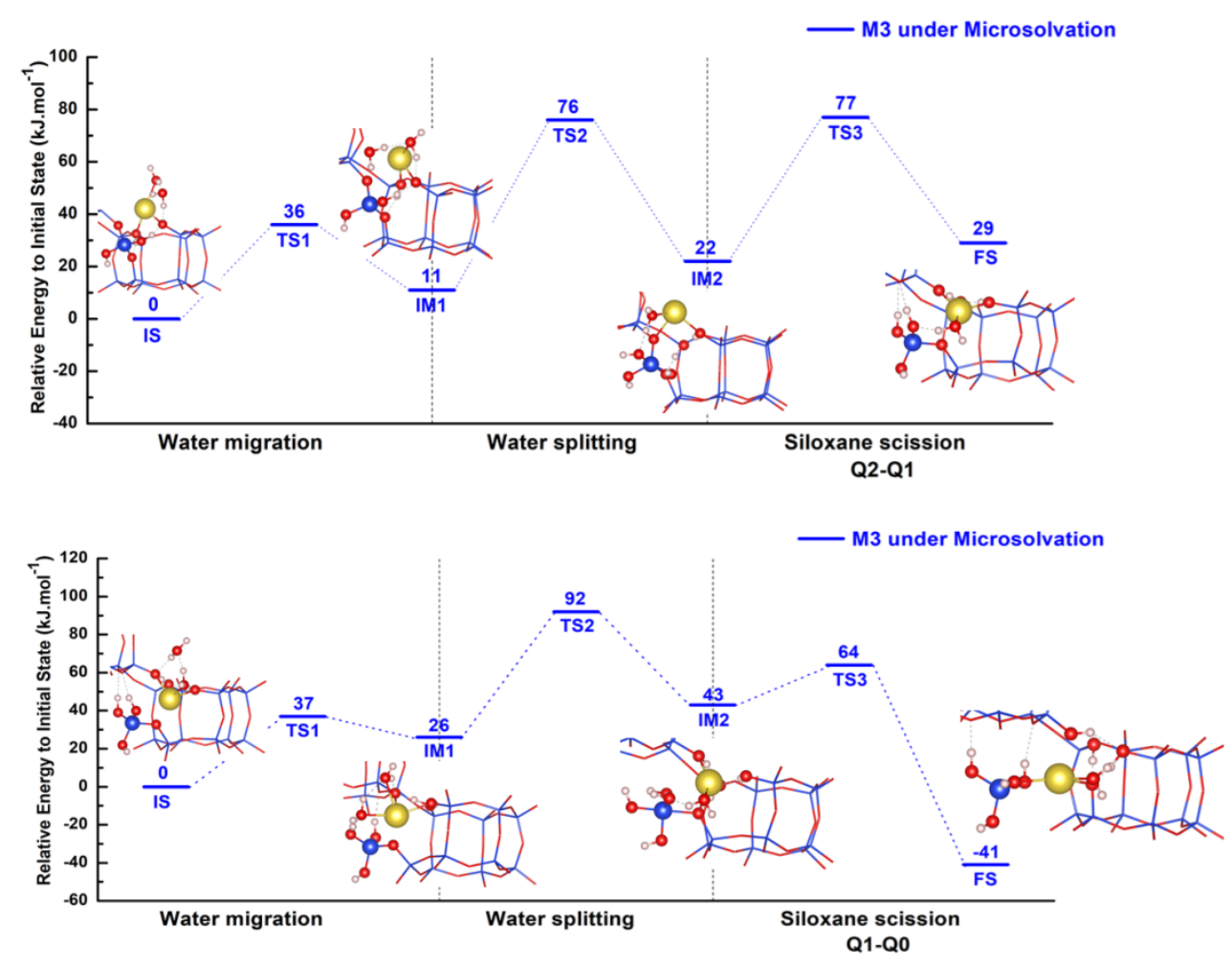

Figure S15: Top) Schematic microsolvation $\mathrm{M} 3$ mechanism for the $\mathrm{Q}^{3} \rightarrow \mathrm{Q}^{2}$ hydrolysis reaction. Attacking water molecules are coloured in blue and green. The $\mathrm{Na}$ and $\mathrm{OH}$ groups from the preceding $\mathrm{NaOH}$-induced $\mathrm{Q}^{4} \rightarrow \mathrm{Q}^{3}$ step are coloured in red. Middle) The full reaction pathway from $\mathrm{Q}^{3} \rightarrow \mathrm{Q}^{0}$ under microsolvation, with gas phase water molecules as the reference for each step. Below) The individual reaction steps for the $\mathrm{Q}^{2} \rightarrow \mathrm{Q}^{1}$ and $\mathrm{Q}^{1} \rightarrow \mathrm{Q}^{0}$ reactions under microsolvation with the initial states of individual steps as references.

\section{M3 mechanism of FER hydrolysis under microsolvation conditions}

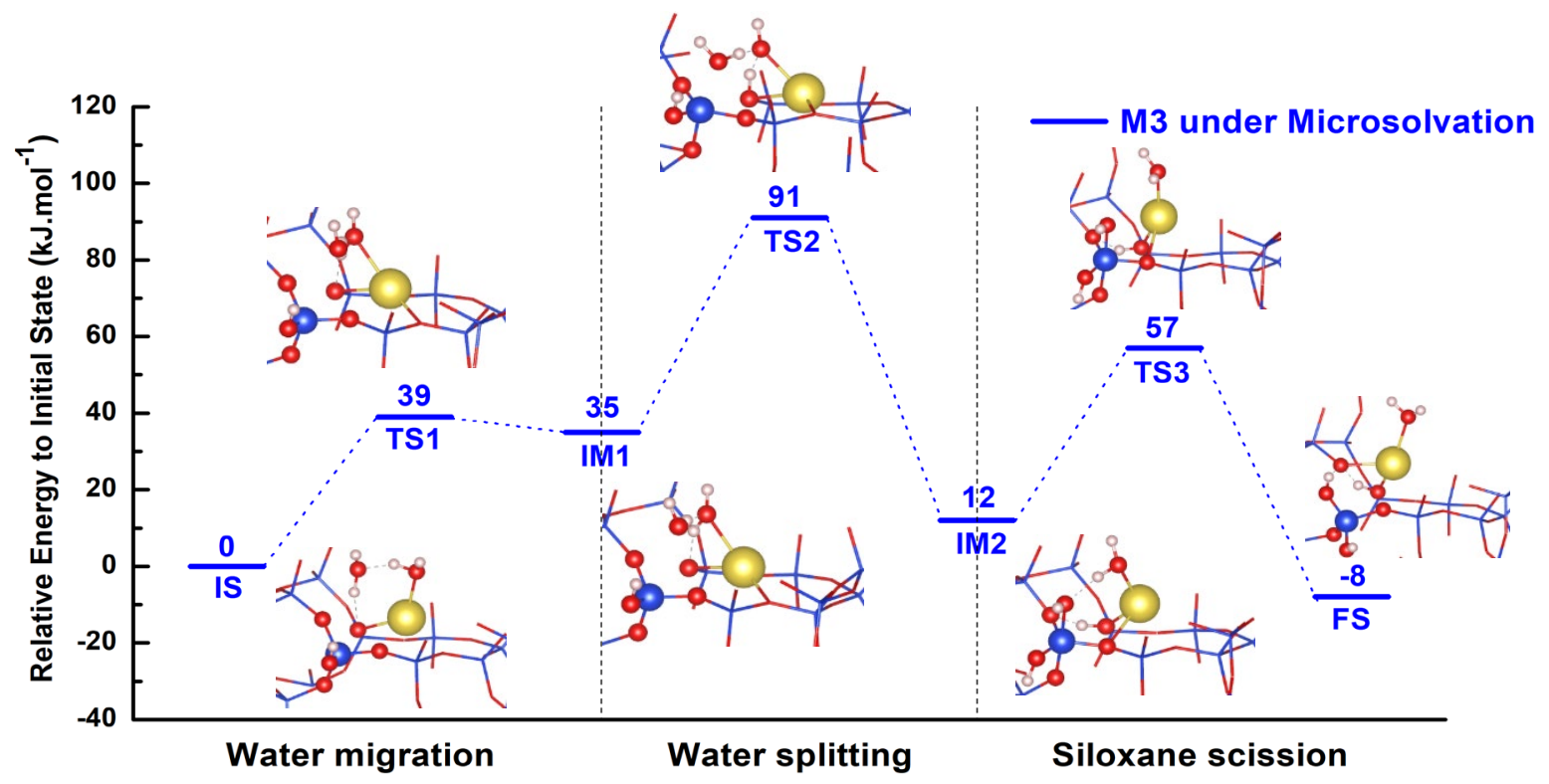

Figure S16: $\mathrm{Q}^{3} \rightarrow \mathrm{Q}^{2}$ mechanism in the silicious ferrierite (FER) framework under microsolvation conditions. 
The $\mathrm{M} 2 \mathrm{Q}^{3}$ product was generated for the FER topology (unit cell parameters: $\mathrm{a}=\mathrm{b}=\mathrm{c}=$ $12.48 \AA, \alpha=80.74^{\circ}, \beta=110.08^{\circ}, \gamma=144.83^{\circ}$ ), in which an Si-O bond in the FER 6-ring was broken, generating a sodium silanolate defect and a $\mathrm{Q}^{3}$ silanol group on silicon $\mathrm{T} 2$. Two water molecules were introduced to the defective framework, and the energetics of the $\mathrm{Q}^{3}$ $\rightarrow \mathrm{Q}^{2} \mathrm{M} 3$ mechanism in CHA were calculated. Despite the significant differences in topology and the smaller accessible volume of FER $\left(10.1 \%\right.$, c.f. $17.3 \%$ in CHA) ${ }^{5}$ the mechanism has very similar activation barriers $(39,56$ and $45 \mathrm{~kJ} / \mathrm{mol}$, c.f. 35,64 and $36 \mathrm{~kJ} / \mathrm{mol}$ in CHA), intermediate energies ( +35 and +12 , c.f. +25 and $+10 \mathrm{~kJ} / \mathrm{mol}$ in CHA) and overall reaction energy (-8, c.f $+2 \mathrm{~kJ} / \mathrm{mol}$ in $\mathrm{CHA})$.

\section{References}

1. Jin, M.; Veselý, O.; Heard, C.; Kubů, M.; Nachtigal, P.; Čejka, J.; Grajciar, L., The Role of Water Loading and Germanium Content in Germanosilicate Hydrolysis. J. Phys. Chem. C 2021 125, (43), 23744-23757.

2. $\quad$ Ott, J. B.; Boerio-Goates, J., Chemical Thermodynamics: Advanced Applications: Advanced Applications, Chapter 11. Elsevier: 2000.

3. Leung, B. O.; Reid, D. L.; Armstrong, D. A.; Rauk, A., Entropies in solution from entropies in the gas phase. J. Phys. Chem. A 2004, 108, (14), 2720-2725.

4. Van Speybroeck, V.; Van Neck, D.; Waroquier, M.; Wauters, S.; Saeys, M.; Marin, G., Ab initio study of radical addition reactions: addition of a primary ethylbenzene radical to ethene (I). J. Phys. Chem. A 2000, 104, (46), 10939-10950.

5. Database of Zeolite Structures http://www.iza-structure.org/databases/ (accessed

Mar 2, 2021). 